\title{
A mathematical model of the effect of subsidy transfer in cooperative advertising using differential game theory
}

\author{
Peter E. Ezimadu ${ }^{1}$
}

Received: 20 October 2017 / Accepted: 12 October 2018 / Published online: 28 October 2018

(c) The Author(s) 2018

\begin{abstract}
This work deals with subsidy transfer from a manufacturer to a retailer through the distributor in cooperative advertising. While the retailer engages in local advertising, the manufacturer indirectly participates in retail advertising using advertising subsidy which is given to the distributor, who in turn transfers it to the retailer. The manufacturer is the Stackelberg game leader; the distributor is the first follower, while the retailer is the last follower. The work employs differential game in modelling the effect of subsidy on the individual and channel payoffs; and models the awareness share dynamics using Sethi's sales-advertising model. It obtains Stackelberg equilibriums characterising four-game scenario: no subsidy from neither the manufacturer nor the distributor; withholding of manufacturer's subsidy by the distributor; provision of subsidy by the distributor in the absence of the manufacturer's participation; and the participation of both the manufacturer and distributor in retail advertising. It shows that in the absence of subsidy from the manufacturer, the distributor should intervene by providing subsidy to the retailer. However, if this is impossible, he should avoid withholding the subsidy meant for retail advertising. The players' payoffs as well as the channel payoff are worst with non-participation of both the manufacturer and the distributor, and best with transfer of subsidy.
\end{abstract}

Keywords Cooperative advertising $\cdot$ Stackelberg game $\cdot$ Differential game $\cdot$ Sethi’s sales-advertising model

\section{Introduction}

Cooperative advertising is an advertising arrangement in which the manufacturer indirectly engages in advertising by subsidising retail advertising (Dutta et al. 1995; Nagler 2006; Bergen and John 1997). By this arrangement, the manufacturer pays for a fraction of the retail advertising expenditure. This serves as a boost to the retail effort geared towards product awareness which eventually leads to more sales of the manufacturer's product (Taylor 1978).

Classical cooperative advertising models generally involve only two parties: the manufacturer(s) and the retailer(s). The manufacturer produces the goods and/or services, while the retailer sells to the end users. It is a wellknown fact that in a normal setting a manufacturer's link to a retailer is usually through the distributor (Webster 1976). The existence of this link implies that the manufacturer's

Peter E. Ezimadu

peterezimadu@yahoo.com

1 Department of Mathematics, Delta State University, Abraka, Nigeria subsidy for retail advertising may need to go through the distributor. It is therefore necessary to consider a channel structure involving the manufacturer, the distributor and the retailer with focus on transfer of subsidy from the manufacturer through the distributor to the retailer.

The rest of the paper is organised as follows: In Sect. 2, we consider a review of related literature on the application of game theory in supply chain and cooperative advertising. This section ends with the motivation for the work. Section 3 deals with the formulation of the differential games involving the retailer, the distributor and the manufacturer. It also contains preliminary results on the players' strategies and payoffs. In Sect. 4, we consider the equilibrium characterising a situation where neither the manufacturer nor the distributor participates in retail advertising. Section 5 deals with the equilibrium characterising the distributor's nontransfer of the manufacturer's provided subsidy for retail advertising. We consider the equilibrium characterising a situation where the distributor subsidises retail advertising in the absence of the manufacturer's participation in Sect. 6 . In Sect. 7, the work deals with the equilibrium characterising a situation where the distributor transfers the manufacturer's 
provided subsidy to the retailer. Section 8 deals with numerical illustrations. Section 9 contains the concluding remarks which include the managerial implications, the limitations and possible extensions of the work.

\section{Literature review}

This work analyses supply chain using game theory. McCain (2014) observes that using game theory in analysing decisions and interactions between parties provides a platform for the combination of economics and mathematics tools which aid in revealing the attitude of players; unveiling the basis of reasonable choices from a set of strategies; and accessing as well as measuring the outcome of chosen strategy. It is therefore necessary to look at some of the applications of game theory in supply chain management. Studies employ game theory in situations where a party's (player's) decision affects or influences the payoff of another party (player) (Carmichael 2005; Geckil and Anderson 2009). In this work, we are modelling a situation where each player's payoff is based on sequential decisions, hence the appeal to game theory. Xiao and Qi (2008) developed a mechanism for coordinating a supply chain in which there is demand disruption using game theory. Yu et al. (2009) applied evolutionary game theory to show how to analyse intrinsic evolutionary mechanism of vendor-managed inventory supply chain. Zhu and Dou (2008) and JaliliNaini et al. (2010) used the concept of game theory to investigate environmental issues associated with supply chain management. Seyedesfahani et al. (2011) applied four-game-theoretic models to consider price coordination and cooperative advertising in a manufacturer-retailer supply chain. Kermani et al. (2012) applied game theory to study a supplier-selection considering price, quality and delivery performance. Ezimadu and Nwozo (2017) used game theory to consider a supply chain in which both the manufacturer and retailer are involved in national and local advertising, respectively. For a detailed look at the application of game theory in supply chain management, the reader can consider Kermani et al. (2012) and Ezimadu and Nwozo (2017).

The origin of cooperative advertising models can be traced to the static model developed by Berger (1972). His idea of cooperative advertising is that of discount allowance from the manufacturer to the retailer to aid retail advertising. This was followed by a number of models on cooperative advertising on a static setting. This includes Dant and Berger (1996), Huang et al. (2002), Wang et al. (2011), Zhang and Xie (2012), Ghadimi et al. (2013), Aust and Buscher (2014), He et al. (2014), Karray and Amin (2015). Although these models seem to be detailed in analysing many of the factors associated with cooperative advertising, their general drawback is in their associated single-period analyses due to their static settings. Thus, these models may not be true representation of reality, hence the need for dynamic model approach (Naik et al. 2005; Chintagunta and Vilcassim 1994; Fruchter and Kalish 1998).

Dynamic models on cooperative advertising appear to be more realistic since they are based on the long-term relationship among a lot factors representing various individual interests of the players involved in the channel. These models employ differential game theory (Chintagunta and Jain 1992; Jørgensen et al. 2003; Karray and Zaccour 2005; He et al. 2011; Chutani and Sethi 2012, 2014; Ezimadu and Nwozo 2017).

In reviewing dynamic advertising models, Huang et al. (2012) observed that based on their demand functions, they can be classified into six groups as follows: Vidale-Wolfe model (Vidale and Wolfe 1957), Lanchester model (Kimball 1957), Nerlove-Arrow model (Nerlove and Arrow 1957), diffusion model (Sethi 1979), dynamic advertising competition models (Prasad and Sethi 2004) and empirical studies of dynamic advertising problems (Chintagunta and Vilcassim 1992). However, only the first three groups stated above are employed in cooperative advertising models (Aust and Buscher 2014).

A lot of dynamic cooperative advertising models are based on Nerlove-Arrow model of goodwill. Jørgensen et al. (2000) were the first to use Nerlove-Arrow model to consider dynamic cooperative advertising. Other works in this group include Jørgensen et al. (2003), Karray and Zaccour (2005), Zhang et al. (2017).

Another group of dynamic cooperative advertising models are based on the Vidale-Wolfe model which was modified in Sethi model (Sethi 1983). Earlier models in this category considered situations where only the retailer is involved in advertising while the manufacturer is indirectly involved through the provision of subsidy. Such models include $\mathrm{He}$ et al. (2009), Chutani and Sethi (2012). Recently Ezimadu and Nwozo (2017) extended He et al. (2009) to consider a situation where both the manufacturer and retailer are directly involved advertising while the manufacturer subsidises the retailer's local advertising expenditure.

The third category uses the Lanchester model (Kimball 1957). The Lanchester model is similar to the Vidale-Wolfe model. It is used to model a market dynamics in which the players' total market share is normalised to 1 . He et al. (2011) is a typical example of a model in this category.

For a detailed overview of the cooperative advertising literature, one can read Aust and Buscher (2014), and Jørgensen and Zaccour (2014).

All the papers on cooperative advertising discussed above are based on the traditional manufacturer-retailer supply chain. This work models a supply channel in which the distributor is incorporated into the traditional manufacturer-retailer supply channel. Thus, the channel involves a 
manufacturer-distributor-retailer channel. The work models a situation in which channel members make decisions as a Stackelberg game. This corresponds with the hierarchical channel setting. The manufacturer is the channel leader, while the distributor and retailer are the first and second (last) followers, respectively. The work considers for the first time a situation where advertising subsidy is transferred from the manufacturer to the retailer through the distributor with only the retailer involved in advertising. To the best of the author's knowledge, this idea of incorporating the distributor into the traditional manufacturer-retailer supply chain together with transfer of subsidy has not been achieved in the cooperative advertising literature.

As stated earlier, with the incorporation of the distributor into the supply chain, the manufacturer may no longer give subsidy directly to the retailer since he is not in direct contact with him. The subsidy may have to pass through the distributor who is expected to transfer same to the retailer. Thus, considering possible reactions towards participation (provision and/or transfer of subsidy) in retail advertising, we will use a four-game scenario to help us study the effect of provision and transfer of subsidy on the advertising effort, the players' payoffs and the channel payoff. Thus, we consider the following equilibrium situations:

(1) A situation where neither the manufacturer nor the distributor participates in retail advertising;

(2) A situation where the manufacturer provides subsidy to be transferred to the retailer, but the distributor fails to act accordingly;

(3) A situation where the manufacturer does not provide subsidy, but the distributor intervenes by providing subsidy to the retailer;

(4) A situation where the distributor transfers the subsidy provided by the manufacturer to the retailer.

The work will obtain feedback Stackelberg equilibriums characterising each of these game scenarios. From this, we will compare the advertising efforts, each player's payoffs and the channel payoffs.

\section{Model formulation}

\section{The components of the game}

The Players The model involves three players: the manufacturer, the distributor and the retailer.

\section{Players' Strategies}

- Retailer's Strategy This is the retailer's local advertising effort $a_{\mathrm{R}}(t), t>0$. We note that the admissible class of decisions $a_{\mathrm{R}}(t), t>0$ are non-negative.

- Distributor's Strategy This is the participation rate $\theta_{\mathrm{D}}(t), t>0$. It is the percentage of the manufacturer's provided subsidy that the distributor is willing to transfer to the retailer.

- Manufacturer's Strategy This is the participation rate $\theta_{\mathrm{M}}(t), t>0$. It is the percentage of the retail advertising expenditure he is willing to subsidise, and as such gives to the retailer through the distributor.

Players' Payoff functions The players' payoff functions $V_{\mathrm{R}}, V_{\mathrm{D}}$ and $V_{\mathrm{M}}$ are the expected rewards enjoyed by the retailer, the distributor and the manufacturer, respectively, at the end of the game.

Timing of the Game The game is modelled over an infinite horizon.

Rules of the Game The work is modelled as a Stackelberg game in which the manufacturer is the channel leader. He is the first to announce his participation rate $\theta_{\mathrm{M}}(t)$. Based on this, the distributor informs the retailer of his participation rate $\theta_{\mathrm{D}}(t)$. Using this information, the retailer decides his advertising effort $a_{\mathrm{R}}(t)$. Thus, the equilibrium is determined by backward induction.

State of the Game The state of the game is the level of the awareness share $x(t)$ at any given time $t>0$. We note that the awareness share is the proportion of the market aware of the product.

In addition to the above components, we have the following notations to aid the model formulation and analysis:

$t$

$x(t) \in[0,1]$

$x_{0} \in[0,1]$

$a_{\mathrm{R}}(t) \geq 0$

$\theta_{\mathrm{D}}(t) \in[0,1]$

$\theta_{\mathrm{M}}(t) \in[0,1]$

$\alpha \in[0,1]$

$\delta>0$

$r>0$

$m_{\mathrm{R}}, m_{\mathrm{D}}, m_{\mathrm{M}}$

$V_{\mathrm{R}}, V_{\mathrm{D}}, V_{\mathrm{M}}$

$T_{\mathrm{R}}, T_{\mathrm{D}}, T_{\mathrm{M}}$
Time $t>0$

The proportion of the market aware of the product at time $t$

Initial proportion of the market aware of the product

Retail advertising effort

Distributor's participation rate

Manufacturer's participation rate

Advertising effectiveness parameter

Awareness share decay parameter

Discount rate

Margins of the retailer, distributor and manufacturer, respectively

Value functions of the retailer, distributor and manufacturer, respectively

Intercepts of the of the value functions of the retailer, distributor and manufacturer, respectively 
$S_{\mathrm{R}}, S_{\mathrm{D}}, S_{\mathrm{M}} \quad$ Slopes (rates of increase) of the value function of the retailer, distributor and manufacturer, respectively

\section{The Players' control problems}

The main purpose of advertising is to gain market awareness which eventually leads to better payoff (Taylor 1978). To achieve this, the retailer involves in local advertising of the product. In traditional cooperative advertising models, the manufacturer participates in retail advertising by subsidising the retail advertising expenditure. The fraction of retail advertising expenditure which the manufacturer is willing to give to the retailer to aid the advertising of the product is called the participation rate. It is also known as subsidy rate. Neither the manufacturer nor the distributor is directly involved in retail advertising. The manufacturer indirectly engages in retail advertising by providing subsidy using the participation rate $\theta_{\mathrm{M}}(t)$. The subsidy is given to the distributor who in turn is expected to transfer the same to the retailer. The distributor's participation rate is $\theta_{\mathrm{D}}(t)$.

Due to the diminishing marginal returns associated with advertising, the cost functions are usually assumed to be quadratic (Chintagunta and Jain 1992; Prasad and Sethi 2004; He et al. 2009; Ezimadu and Nwozo 2017). Based on this, we have that the advertising expenditure of the manufacturer, the distributor and the retailer are $\theta_{\mathrm{M}}(t) a_{\mathrm{R}}(t)^{2}$, $\left(\theta_{\mathrm{D}}(t)-\theta_{\mathrm{M}}(t)\right) a_{\mathrm{R}}(t)^{2}$ and $\theta_{\mathrm{D}}(t) a_{\mathrm{R}}(t)^{2}$, respectively.

The awareness share of the product is very important to the channel members. Its dynamics depends on the advertising effort. To model the awareness share dynamics, we use a modification of Sethi's sales-advertising model (Sethi 1983). The dynamics is given by

$x^{\prime}(t)=a_{\mathrm{R}}\left(x(t) \mid \theta_{\mathrm{D}}(t), \theta_{\mathrm{M}}(t)\right) \alpha \sqrt{1-x(t)}-\delta x(t), x(0)=x_{0} \in[0,1]$

where $x(t)$ is market awareness, also known as awareness share. It is the proportion of the market population aware of the product. $\alpha \in[0,1]$ is the response constant, also known as the advertising effectiveness parameter. It indicates the response to advertising. $\delta$ is the decay rate. It represents the rate of decay of the product awareness share resulting from forgetfulness, product obsolesce and competition.

The manufacturer is considered to be the game leader. $\mathrm{He}$ is the first channel member that makes decision. He informs the distributor of his participation rate $\theta_{\mathrm{M}}(t) \in[0,1]$ which should be transferred to the retailer. The distributor in turn informs the retailer of the subsidy rate $\theta_{\mathrm{D}}\left(x(t) \mid \theta_{\mathrm{M}}(t)\right) \in[0,1]$ to be given to him. In reaction to these, the retailer decides on his advertising effort $a_{\mathrm{R}}\left(x(t) \mid \theta_{\mathrm{D}}(t), \theta_{\mathrm{M}}(t)\right)$. This is done by solving the optimal control problem
$V_{\mathrm{R}}(x(t))=\max _{a_{\mathrm{R}}\left(x(t) \mid \theta_{\mathrm{D}}(t), \theta_{\mathrm{M}}(t)\right) \geq 0} \int_{0}^{\infty} e^{-r t}$

$\left[m_{\mathrm{R}} x(t)-\left(1-\theta_{\mathrm{D}}(t)\right) a_{\mathrm{R}}\left(x(t) \mid \theta_{\mathrm{D}}(t), \theta_{\mathrm{M}}(t)\right)^{2}\right] \mathrm{d} t$

subject to (1), where $V_{\mathrm{R}}$ is the retailer's payoff function, $r$ is the discount rate, and $m_{\mathrm{R}}$ is the retailer's margin.

In expectation of the retailer's response, the distributor incorporates the same (that is the retailer's response) into his maximisation problem to determine his participation rate $\theta_{\mathrm{D}}(t)\left(x(t) \mid \theta_{\mathrm{M}}(t)\right) \in[0,1]$. Thus, his optimal control problem is given by

$V_{\mathrm{D}}(x(t))=\max _{0 \leq \theta_{\mathrm{D}}(t) \leq 1} \int_{0}^{\infty} e^{-r t}$

$\left[m_{\mathrm{D}} x(t)-\left(\theta_{\mathrm{D}}\left(x(t) \mid \theta_{\mathrm{M}}(t)\right)-\theta_{\mathrm{M}}(t)\right) \times a_{\mathrm{R}}\left(x(t) \mid \theta_{\mathrm{D}}(t), \theta_{\mathrm{M}}(t)\right)^{2}\right] \mathrm{d} t$

$x^{\prime}(t)=a_{\mathrm{R}}\left(x(t) \mid \theta_{\mathrm{D}}(t), \theta_{\mathrm{M}}(t)\right) \alpha \sqrt{1-x(t)}-\delta x(t), x(0)=x_{0} \in[0,1]$,

where $V_{\mathrm{D}}$ and $m_{\mathrm{D}}$ are the distributor's payoff function and margin, respectively.

Finally, in anticipation of the distributor's response, the manufacturer incorporates the distributor's response into his control problem to determine his participation rate $\theta_{\mathrm{M}}(t)$. Thus, his optimal control problem is given by

$V_{\mathrm{M}}(x(t))=\max _{0 \leq \theta_{\mathrm{M}}(t) \leq 1} \int_{0}^{\infty} e^{-r t}\left[m_{\mathrm{M}} x(t)-\theta_{\mathrm{M}}(t) a_{\mathrm{R}}\left(x(t) \mid \theta_{\mathrm{D}}(t), \theta_{\mathrm{M}}(t)\right)^{2}\right] \mathrm{d} t$

$x^{\prime}(t)=a_{\mathrm{R}}\left(x(t) \mid \theta_{\mathrm{D}}(t), \theta_{\mathrm{M}}(t)\right) \alpha \sqrt{1-x(t)}-\delta x(t), x(0)=x_{0} \in[0,1]$

where $V_{\mathrm{M}}$ and $m_{\mathrm{M}}$ are the manufacturer's payoff function and margin, respectively.

\section{The Players' strategies and payoffs}

From (1) and (2), we have the Hamilton-Jacobi-Bellman (HJB) equation for the retailer as

$$
\begin{aligned}
& r V_{\mathrm{R}}(x(t))=\max _{a_{\mathrm{R}}\left(x(t) \mid \theta_{\mathrm{D}}(t), \theta_{\mathrm{M}}(t)\right) \geq 0} \\
& \left\{m_{\mathrm{R}} x(t)-\left(1-\theta_{\mathrm{D}}(t)\right) a_{\mathrm{R}}\left(x(t) \mid \theta_{\mathrm{D}}(t), \theta_{\mathrm{M}}(t)\right)^{2}\right. \\
& \left.+V_{\mathrm{R} x}\left[a_{\mathrm{R}}\left(x(t) \mid \theta_{\mathrm{D}}(t), \theta_{\mathrm{M}}(t)\right) \alpha \sqrt{1-x(t)}-\delta x(t)\right]\right\}
\end{aligned}
$$

To simplify our discussion, we remove the arguments wherever there is no ambiguity. Thus, we have that 
$r V_{\mathrm{R}}(x)=\max _{a_{\mathrm{R}} \geq 0}\left\{m_{\mathrm{R}} x-\left(1-\theta_{\mathrm{D}}\right) a_{\mathrm{R}}^{2}+V_{\mathrm{R} x}\left[a_{\mathrm{R}} \alpha \sqrt{1-x}-\delta x\right]\right\} . \quad \Rightarrow \theta_{\mathrm{D}}=\frac{2 \theta_{\mathrm{M}} V_{\mathrm{R} x}+2 V_{\mathrm{D} x}-1}{1+2 V_{\mathrm{D} x}}$.

Maximising (7) with respect to $a_{\mathrm{R}}$, we have that the FOC (first-order condition) for an interior solution is

$-2\left(1-\theta_{\mathrm{D}}\right) a_{\mathrm{R}}+\alpha V_{\mathrm{R} x} \sqrt{1-x}=0$

$\Rightarrow a_{\mathrm{R}}\left(x \mid \theta_{\mathrm{D}}, \theta_{\mathrm{M}}\right)=\frac{\alpha V_{\mathrm{R} x} \sqrt{1-x}}{2\left(1-\theta_{\mathrm{D}}\right)}$.

Using (8) in (7), we have

$r V_{\mathrm{R}}(x)=m_{\mathrm{R}} x+\frac{\alpha^{2} V_{\mathrm{R} x}^{2}(1-x)}{4\left(1-\theta_{\mathrm{D}}\right)}-\delta V_{\mathrm{R} x} x$

From the discussion above, we have the next result.

Proposition 1 Suppose the distributor's participation rate is known, then the retail advertising effort is given by (8) and the payoff is given by (9).

From (8), we observe that despite the fact that both the manufacturer and the distributor are involved in retail advertising, the distributor's action regarding subsidy goes a long way to affect the advertising effort. It is clear that that $a_{\mathrm{R}}$ increases with $\theta_{\mathrm{D}}$. However, the subsidy must not be total. This is because as $\theta_{\mathrm{D}} \rightarrow 1$ (that is total subsidy), $a_{\mathrm{R}}$ becomes unbounded. Since it makes no sense for the retailer to engage in unbounded advertising expenditure, it follows that $\theta_{\mathrm{D}} \neq 1$. Also, looking at (9) we observe that $\theta_{\mathrm{D}}$ also greatly influences $V_{\mathrm{R}}$. Obviously, a high level of $\theta_{\mathrm{D}}$ will imply a large $V_{\mathrm{R}}$.

Now, from (3) and (4) we have the HJB equation

$r V_{\mathrm{D}}(x)=\max _{0 \leq \theta_{\mathrm{D}} \leq 1}\left\{m_{\mathrm{D}} x-\left(\theta_{\mathrm{D}}-\theta_{\mathrm{M}}\right) a_{\mathrm{R}}^{2}+V_{\mathrm{D} x}\left[a_{\mathrm{R}} \alpha \sqrt{1-x}-\delta x\right]\right\}$.

Putting (8) into (10), we have

From (5) and (6), we have the HJB equation

$r V_{M}(x)=\max _{0 \leq \theta_{M} \leq 1}\left\{m_{M} x-\theta_{M} a_{R}^{2}+V_{M x}\left[a_{R} \alpha \sqrt{1-x}-\delta x\right]\right\}$.

Also putting (8) into (13), we have

$$
\begin{aligned}
r V_{\mathrm{M}}(x)= & \max _{0 \leq \theta_{\mathrm{M}} \leq 1}\left\{m_{\mathrm{M}} x-\theta_{\mathrm{M}} \frac{\alpha^{2} V_{\mathrm{R} x}^{2}(1-x)}{4\left(1-\theta_{\mathrm{D}}\right)^{2}}\right. \\
& \left.+V_{\mathrm{M} x}\left[\frac{\alpha^{2} V_{\mathrm{R} x}(1-x)}{2\left(1-\theta_{\mathrm{D}}\right)}-\delta x\right]\right\} .
\end{aligned}
$$

Putting (12) in (14), we have

$$
\begin{aligned}
r V_{\mathrm{M}}(x)= & \max _{0 \leq \theta_{\mathrm{M}} \leq 1}\left\{m_{\mathrm{M}} x-\frac{\theta_{\mathrm{M}} \alpha^{2} V_{\mathrm{R} x}^{2}\left(1+2 V_{\mathrm{D} x}\right)^{2}(1-x)}{16\left(1-\theta_{\mathrm{M}} V_{\mathrm{R} x}\right)^{2}}\right. \\
& \left.+\frac{\alpha^{2} V_{\mathrm{R} x} V_{\mathrm{M} x}\left(1+2 V_{\mathrm{D} x}\right)^{2}(1-x)}{4\left(1-\theta_{\mathrm{M}} V_{\mathrm{R} x}\right)}-\delta V_{\mathrm{M} x} x\right\}
\end{aligned}
$$

Applying the FOC for a maximum with respect to $\theta_{\mathrm{M}}$ in (15), we have

$$
\begin{aligned}
& \frac{\alpha^{2} V_{\mathrm{R} x}^{2}\left(1+2 V_{\mathrm{D} x}\right)^{2}(1-x)}{4}\left[\frac{\left(2-2 \theta_{\mathrm{M}} V_{\mathrm{R} x}\right)^{2}+4 \theta_{\mathrm{M}}\left(2-2 \theta_{\mathrm{M}} V_{\mathrm{R} x}\right) V_{\mathrm{R} x}}{\left(2-2 \theta_{\mathrm{M}} V_{\mathrm{R} x}\right)^{4}}\right] \\
& -\frac{2 \alpha^{2} V_{\mathrm{R} x}^{2} V_{\mathrm{M} x}\left(1+2 V_{\mathrm{D} x}\right)(1-x)}{2\left(2-2 \theta_{\mathrm{M}} V_{\mathrm{R} x}\right)^{2}}=0 .
\end{aligned}
$$$$
\Rightarrow \theta_{\mathrm{M}}=\frac{4 V_{\mathrm{M} x}-2 V_{\mathrm{D} x}-1}{V_{\mathrm{R} x}\left[4 V_{\mathrm{M} x}+2 V_{\mathrm{D} x}+1\right]} .
$$

Using (16) in (12), we have

$$
\begin{aligned}
r V_{\mathrm{D}}(x) & =\max _{0 \leq \theta_{\mathrm{D}} \leq 1}\left\{m_{\mathrm{D}} x-\left(\theta_{\mathrm{D}}-\theta_{\mathrm{M}}\right)\left(\frac{\alpha V_{\mathrm{R} x} \sqrt{1-x}}{2\left(1-\theta_{\mathrm{D}}\right)}\right)^{2}+V_{\mathrm{D} x}\left[\frac{\alpha V_{\mathrm{R} x} \sqrt{1-x}}{2\left(1-\theta_{\mathrm{D}}\right)} \alpha \sqrt{1-x}-\delta x\right]\right\} \\
& =\max _{0 \leq \theta_{\mathrm{D}} \leq 1}\left\{m_{\mathrm{D}} x-\frac{\left(\theta_{\mathrm{D}}-\theta_{\mathrm{M}}\right) \alpha^{2} V_{\mathrm{R} x}^{2}(1-x)}{4\left(1-\theta_{\mathrm{D}}\right)^{2}}+\frac{2 \alpha^{2} V_{\mathrm{D} x} V_{\mathrm{R} x}(1-x)}{4\left(1-\theta_{\mathrm{D}}\right)}-V_{\mathrm{D} x} \delta x\right\} .
\end{aligned}
$$

Maximising (11) with respect $\theta_{\mathrm{D}}$, we have

$$
\frac{\alpha^{2} V_{\mathrm{R} x}^{2}\left[4\left(1-\theta_{\mathrm{D}}\right)^{2}+8 \theta_{\mathrm{D}}\left(1-\theta_{\mathrm{D}}\right)\right](1-x)}{16\left(1-\theta_{\mathrm{D}}\right)^{4}}-\frac{4 \alpha^{2} \theta_{\mathrm{M}} V_{\mathrm{R} x}^{2}(1-x)}{8\left(1-\theta_{\mathrm{D}}\right)^{3}}-\frac{2 \alpha^{2} V_{\mathrm{D} x} V_{\mathrm{R} x}(1-x)}{4\left(1-\theta_{\mathrm{D}}\right)^{2}}=0
$$


$\theta_{\mathrm{D}}=\frac{2\left(4 V_{\mathrm{M} x}-2 V_{\mathrm{D} x}-1\right)}{\left(2 V_{\mathrm{D} x}+1\right)\left(4 V_{\mathrm{M} x}+2 V_{\mathrm{D} x}+1\right)}+\frac{2 V_{\mathrm{D} x}-1}{2 V_{\mathrm{D} x}+1}$.

From the above discussion, we have the following result:

Proposition 2 Given the differential games (1) to (6), the distributor and manufacturer's participation rates are given by

$\theta_{\mathrm{D}}=\left\{\begin{array}{l}\frac{2\left(4 V_{\mathrm{M} x}-2 V_{\mathrm{D} x}-1\right)}{\left(2 V_{\mathrm{D} x}+1\right)\left(4 V_{\mathrm{Mx}}+2 V_{\mathrm{D} x}+1\right)}+\frac{2 V_{\mathrm{D} x}-1}{2 V_{\mathrm{D} x}+1} \\ 0 \text { otherwise }\end{array}\right.$

and

$\theta_{\mathrm{M}}=\left\{\begin{array}{l}\frac{4 V_{\mathrm{Mx}}-2 V_{\mathrm{Dx}}-1}{V_{\mathrm{Rx}}\left[4 V_{\mathrm{Mx}}+2 V_{\mathrm{Dx}}+1\right]} \\ 0 \quad \text { otherwise }\end{array}\right.$,

respectively, while their payoffs are given by (11) and (15), respectively.

Equation (19) shows that a certain condition must be satisfied before the manufacturer can participate in retail advertising. This is to ensure that he is not short-changed. The condition

$4 V_{\mathrm{M} x}>2 V_{\mathrm{D} x}+1$

must be satisfied. A similar picture is clear in (18) which shows that for the distributor to transfer subsidy to the retailer the condition

$8 V_{\mathrm{D} x} V_{\mathrm{M} x}+4 V_{\mathrm{D} x}^{2}+4 V_{\mathrm{M} x}>4 V_{\mathrm{D} x}+3$

has to be satisfied; else the distributor will withhold the subsidy.

Considering (15) in conjunction with (14), we observe that it is not advisable for the manufacturer to totally subsidise retail advertising. This is also the case with (11).

\section{Game equilibrium characterising non-provision of subsidy}

In this section, we consider a situation where neither the manufacturer nor the distributor participates in retail advertising.

Proposition 3 Suppose that neither the manufacturer nor the distributor participates in retail advertising, then the retail advertising effort is given by

$a_{\mathrm{R}}\left(x \mid \theta_{\mathrm{D}}, \theta_{\mathrm{M}}\right)=\frac{\alpha S_{\mathrm{R}} \sqrt{1-x}}{2}$, and players' payoffs are given by

$r V_{\mathrm{R}}(x)=m_{\mathrm{R}} x+\frac{\alpha^{2} S_{\mathrm{R}}^{2}(1-x)}{4}-\delta S_{\mathrm{R}} x$,

$r V_{\mathrm{D}}(x)=m_{\mathrm{D}} x+\frac{\alpha^{2} S_{\mathrm{R}} S_{\mathrm{D}}(1-x)}{2}-\delta S_{\mathrm{D}} x$,

$r V_{\mathrm{M}}(x)=m_{\mathrm{M}} x+\frac{\alpha^{2} S_{\mathrm{R}} S_{\mathrm{M}}(1-x)}{2}-\delta S_{\mathrm{M}} x$,

where

$S_{\mathrm{R}}=\frac{4 m_{\mathrm{R}}}{\alpha^{2} S_{\mathrm{R}}+4(r+\delta)}$,

$S_{\mathrm{D}}=\frac{2 m_{\mathrm{D}}}{\alpha^{2} S_{\mathrm{R}}+2(r+\delta)}$

$S_{\mathrm{M}}=\frac{2 m_{\mathrm{M}}}{\alpha^{2} S_{\mathrm{R}}+2(r+\delta)}$.

Proof Since neither the manufacturer nor the distributor participates in advertising, we have that $\theta_{\mathrm{D}}=\theta_{\mathrm{M}}=0$. Thus, (8) becomes

$a_{\mathrm{R}}\left(x \mid \theta_{\mathrm{D}}, \theta_{\mathrm{M}}\right)=\frac{\alpha V_{\mathrm{R} x} \sqrt{1-x}}{2}$,

Equation (19) becomes

$r V_{\mathrm{R}}(x)=m_{\mathrm{R}} x+\frac{\alpha^{2} V_{\mathrm{R} x}^{2}(1-x)}{4}-\delta V_{\mathrm{R} x} x$.

Equation (11) becomes

$r V_{\mathrm{D}}(x)=m_{\mathrm{D}} x+\frac{\alpha^{2} V_{\mathrm{R} x} V_{\mathrm{D} x}(1-x)}{2}-\delta V_{\mathrm{D} x} x$.

Further (14) becomes

$r V_{\mathrm{M}}(x)=m_{\mathrm{M}} x+\frac{\alpha^{2} V_{\mathrm{R} x} V_{\mathrm{M} x}(1-x)}{2}-\delta V_{\mathrm{M} x} x$.

Let

$V_{\mathrm{R}}(x)=T_{\mathrm{R}}+S_{\mathrm{R}} x$,

$\Rightarrow V_{\mathrm{R} x}=S_{\mathrm{R}}$.

We similarly let

$V_{\mathrm{D}}(x)=T_{\mathrm{D}}+S_{\mathrm{D}} x$,

$\Rightarrow V_{\mathrm{D} x}=S_{\mathrm{D}}$.

Also, let

$V_{\mathrm{M}}(x)=T_{\mathrm{M}}+S_{\mathrm{M}} x$,

$\Rightarrow V_{\mathrm{M} x}=S_{\mathrm{M}}$. 
Using (32) in (27), we have (20).

Using (31) and (32) in (28), we have

$r V_{\mathrm{R}}(x)=r\left(T_{\mathrm{R}}+S_{\mathrm{R}} x\right)=m_{\mathrm{R}} x+\frac{\alpha^{2} S_{\mathrm{R}}^{2}(1-x)}{4}-\delta S_{\mathrm{R}} x$.

Equating the coefficients of $x$, we have (24).

Using (32), (33) and (34) in (29), we have

$r V_{D}(x)=r\left(T_{D}+S_{D} x\right)=m_{D} x+\frac{\alpha^{2} S_{R} S_{D}(1-x)}{2}-\delta S_{D} x$.

Equating the coefficients of $x$, we have (25).

Equating constants, we have

Using (32), (35) and (36) in (30), we have

$r V_{\mathrm{M}}(x)=r\left(T_{\mathrm{M}}+S_{\mathrm{M}} x\right)=m_{\mathrm{M}} x+\frac{\alpha^{2} S_{\mathrm{R}} S_{\mathrm{M}}(1-x)}{2}-\delta S_{\mathrm{M}} x$

Equating the coefficients of $x$, we have (26).

From (20), we observe that with non-availability of subsidy the retailer's advertising effort depends on the rate of increase of his payoff. Now, looking at (21), (22) and (23) we observe from the second term on the right hand side that this rate of increase is pivotal to the payoff of the retailer, the distributor and the manufacturer, respectively. Thus, a low individual player's payoff and particularly channel payoff are expected since there is no motivation (from the other players) for the retailer.

\section{Game equilibrium charactering non-transfer of the manufacturer's provided subsidy to the retailer}

Let us consider a situation where the manufacturer's provided subsidy meant for retail advertising is withheld by the distributor. Since the manufacturer is not in direct contact with the retailer, he gives the subsidy to the distributor who is the middleman (link) between the two players. There is the tendency for the distributor not to transfer the provided subsidy to the retailer. The next result gives the Stackelberg equilibrium characterising non-transfer of the provided subsidy.

Proposition 4 Suppose the manufacturer envisages that the distributor may not transfer the provided subsidy to the retailer, then the manufacturer's subsidy rate is given by

$\theta_{\mathrm{M}}=\frac{1-2 S_{\mathrm{D}}}{2 S_{\mathrm{R}}}$,

the retail advertising effort is given by

$a_{\mathrm{R}}\left(x \mid \theta_{\mathrm{D}}, \theta_{\mathrm{M}}\right)=\frac{\alpha S_{\mathrm{R}} \sqrt{1-x}}{2}$,

while the players' payoffs are given by $r V_{\mathrm{R}}(x)=m_{\mathrm{R}} x+\frac{\alpha^{2} S_{\mathrm{R}}^{2}(1-x)}{4}-\delta S_{\mathrm{R}} x$,

$r V_{\mathrm{D}}(x)=m_{\mathrm{D}} x+\frac{\alpha^{2} S_{\mathrm{R}}\left(1-2 S_{\mathrm{D}}\right)(1-x)}{8}+\frac{\alpha^{2} S_{\mathrm{R}} S_{\mathrm{D}}(1-x)}{2}-S_{\mathrm{D}} \delta x$,

$r V_{\mathrm{M}}(x)=m_{\mathrm{M}} x+\frac{\alpha^{2} S_{\mathrm{R}}\left(1-2 S_{\mathrm{D}}\right)(1-x)}{8}+\frac{\alpha^{2} S_{\mathrm{R}} S_{\mathrm{M}}(1-x)}{2}-\delta S_{\mathrm{M}} x$,

where

$S_{\mathrm{R}}=\frac{4 m_{\mathrm{R}}}{\alpha^{2} S_{\mathrm{R}}+4(r+\delta)}$,

$S_{\mathrm{D}}=\frac{8 m_{\mathrm{D}}-\alpha^{2} S_{\mathrm{R}}}{8(r+\delta)+2 \alpha^{2} S_{\mathrm{R}}}$,

$S_{\mathrm{M}}=\frac{8 m_{\mathrm{M}}+\alpha^{2} S_{\mathrm{R}}\left(1-2 S_{\mathrm{D}}\right)}{4 \alpha^{2} S_{\mathrm{R}}+8(r+\delta)}$.

Proof Since the manufacturer's provided subsidy is not transferred to the retailer, we have that $\theta_{\mathrm{D}}=0, \theta_{\mathrm{M}}>0$. Thus, from (12) we have

$0=\frac{2 \theta_{\mathrm{M}} V_{\mathrm{R} x}+2 V_{\mathrm{D} x}-1}{1+2 V_{\mathrm{D} x}}$

$\Rightarrow \theta_{\mathrm{M}}=\frac{1-2 V_{\mathrm{D} x}}{2 V_{\mathrm{R} x}}$.

Since $\theta_{\mathrm{D}}=0$, (8) becomes

$a_{\mathrm{R}}\left(x \mid \theta_{\mathrm{D}}, \theta_{\mathrm{M}}\right)=\frac{\alpha V_{\mathrm{R} x} \sqrt{1-x}}{2}$.

Using $\theta_{\mathrm{D}}=0$ in (9), we have

$r V_{\mathrm{R}}(x)=m_{\mathrm{R}} x+\frac{\alpha^{2} V_{\mathrm{R} x}^{2}(1-x)}{4}-\delta V_{\mathrm{R} x} x$.

Using $\theta_{\mathrm{D}}=0$ and (45) in (11), we have

$$
\begin{aligned}
r V_{\mathrm{D}}(x)= & m_{\mathrm{D}} x+\frac{\alpha^{2} V_{\mathrm{R} x}\left(1-2 V_{\mathrm{D} x}\right)(1-x)}{8} \\
& +\frac{\alpha^{2} V_{\mathrm{R} x} V_{\mathrm{D} x}(1-x)}{2}-V_{\mathrm{D} x} \delta x .
\end{aligned}
$$

Using $\theta_{\mathrm{D}}=0$ and (45) in (14), we have

$$
\begin{aligned}
r V_{\mathrm{M}}(x)= & m_{\mathrm{M}} x-\frac{\alpha^{2} V_{\mathrm{R} x}\left(1-2 V_{\mathrm{D} x}\right)(1-x)}{8} \\
& +\frac{\alpha^{2} V_{\mathrm{R} x} V_{\mathrm{M} x}(1-x)}{2}-\delta V_{\mathrm{M} x} x .
\end{aligned}
$$


Let

$$
\begin{aligned}
& V_{\mathrm{R}}(x)=T_{\mathrm{R}}+S_{\mathrm{R}} x, \\
& \Rightarrow V_{\mathrm{R} x}=S_{\mathrm{R}} . \\
& \quad \text { Similarly let } \\
& V_{\mathrm{D}}(x)=T_{\mathrm{D}}+S_{\mathrm{D}} x, \\
& \Rightarrow V_{\mathrm{D} x}=S_{\mathrm{D}} .
\end{aligned}
$$

Also let

$V_{\mathrm{M}}(x)=T_{\mathrm{M}}+S_{\mathrm{M}} x$,

$\Rightarrow V_{\mathrm{M} x}=S_{\mathrm{M}}$.

Using (51) and (53) in (45), we have (37).

Also using (51) in (46), we have (38).

Using (50) and (51) in (47), we have

$r V_{\mathrm{R}}(x)=r\left(T_{\mathrm{R}}+S_{\mathrm{R}} x\right)=m_{\mathrm{R}} x+\frac{\alpha^{2} S_{\mathrm{R}}^{2}(1-x)}{4}-\delta S_{\mathrm{R}} x$.

Equating the coefficients of $x$, we have (42).

Using (51), (52) and (53) in (48), we have

$$
\begin{aligned}
r V_{\mathrm{D}}(x)= & r\left(T_{\mathrm{D}}+S_{\mathrm{D}} x\right)=m_{\mathrm{D}} x+\frac{\alpha^{2} S_{\mathrm{R}}\left(1-2 S_{\mathrm{D}}\right)(1-x)}{8} \\
& +\frac{\alpha^{2} S_{\mathrm{R}} S_{\mathrm{D}}(1-x)}{2}-S_{\mathrm{D}} \delta x
\end{aligned}
$$

Equating the coefficients of $x$, we have (43).

Using (51), (53), (54) and (55) in (49), we have

$$
\begin{aligned}
r V_{\mathrm{M}}(x)= & r\left(T_{\mathrm{M}}+S_{\mathrm{M}} x\right)=m_{\mathrm{M}} x+\frac{\alpha^{2} S_{\mathrm{R}}\left(1-2 S_{\mathrm{D}}\right)(1-x)}{8} \\
& +\frac{\alpha^{2} S_{\mathrm{R}} S_{\mathrm{M}}(1-x)}{2}-\delta S_{\mathrm{M}} x
\end{aligned}
$$

Equating the coefficients of $x$, we have (44).

We observe that when the distributor fails to transfer the provided subsidy to the retailer, the retail advertising effort is given by (38) which is the same for the case when neither the manufacturer nor the distributor participates in retail advertising. This leads to the retailer having exactly the same payoff as in the case where neither of them participates in advertising. Further, we observe from this that the rate of increase of the retailer's payoff is a very important determinant of the advertising effort.

This low motivation for advertising resulting from nontransfer of subsidy eventually affects each channel member. This is because a low $a_{\mathrm{R}}$ will imply a low $S_{\mathrm{R}}$, and a low $S_{\mathrm{R}}$ will imply low individual player's payoff, particularly the manufacturer's payoff.

From (40), we observe that the unmotivated retailer with low $S_{\mathrm{R}}$ will negatively influence the distributor's payoff. Thus, the distributor does not gain much by withholding the subsidy. A more pathetic case is that of the manufacturer in (41) since his expenditure (subsidy) was not transferred, coupled with the effect of low awareness resulting from low retail advertising. Thus, it is obvious that all the players are affected by the non-transfer of subsidy. Particularly surprising is that the distributor is not better-off by withholding the subsidy. We will see this clearly later in the numerical illustration. The consequence is that the channel payoff/performance will be relatively low.

\section{Game equilibrium characterising the distributor's provision of subsidy in the absence of the manufacturer's participation in retail advertising}

Suppose the manufacturer is indifferent towards retail advertising. There is the possibility that the distributor may decide to support the retailer. The next result characterises the distributor's provision of subsidy when the manufacturer is indifferent.

Proposition 5 Suppose that the manufacturer does not participate in retail advertising, whereas the distributor does, then the distributor's participation rate is given by

$\theta_{\mathrm{D}}=\frac{2 S_{\mathrm{D}}-1}{2 S_{\mathrm{D}}+1}$

the advertising effort is given by

$a_{\mathrm{R}}\left(x \mid \theta_{\mathrm{D}}, \theta_{\mathrm{M}}\right)=\frac{\alpha S_{\mathrm{R}}\left(2 S_{\mathrm{D}}+1\right) \sqrt{1-x}}{4}$,

and the players' payoffs are given by

$r V_{\mathrm{R}}(x)=m_{\mathrm{R}} x+\frac{\alpha^{2} S_{\mathrm{R}}^{2}\left(2 S_{\mathrm{D}}+1\right)(1-x)}{8}-\delta S_{\mathrm{R}} x$,

$$
\begin{aligned}
r V_{\mathrm{D}}(x)= & m_{\mathrm{D}} x-\frac{\alpha^{2} S_{\mathrm{R}}^{2}\left(2 S_{\mathrm{D}}-1\right)\left(2 S_{\mathrm{D}}+1\right)(1-x)}{16} \\
& +\frac{\alpha^{2} S_{\mathrm{R}} S_{\mathrm{D}}\left(2 S_{\mathrm{D}}+1\right)(1-x)}{4}-\delta S_{\mathrm{D}} x,
\end{aligned}
$$

$r V_{\mathrm{M}}(x)=m_{\mathrm{M}} x+\frac{\alpha^{2} S_{\mathrm{R}} S_{\mathrm{M}}\left(2 S_{\mathrm{D}}+1\right)(1-x)}{4}-\delta S_{\mathrm{M}} x$,

where

$S_{\mathrm{R}}=\frac{8 m_{\mathrm{R}}}{\alpha^{2} S_{\mathrm{R}}\left(2 S_{\mathrm{D}}+1\right)+8(r+\delta)}$, 
$S_{\mathrm{D}}=\frac{16 m_{\mathrm{D}}+\alpha^{2} S_{\mathrm{D}}^{2}\left(2 S_{\mathrm{D}}-1\right)\left(2 S_{\mathrm{D}}+1\right)}{4 \alpha^{2} S_{\mathrm{R}} S_{\mathrm{D}}\left(2 S_{\mathrm{D}}+1\right)+16(r+\delta)}$,

$S_{\mathrm{M}}=\frac{4 m_{\mathrm{M}}}{\alpha^{2} S_{\mathrm{R}}\left(2 S_{\mathrm{D}}+1\right)+4(r+\delta)}$.

Proof From (12), when $\theta_{\mathrm{M}}=0$, we have that

$\theta_{\mathrm{D}}=\frac{2 V_{\mathrm{D} x}-1}{2 V_{\mathrm{D} x}+1}$

so that (8) becomes

$a_{\mathrm{R}}\left(x \mid \theta_{\mathrm{D}}, \theta_{\mathrm{M}}\right)=\frac{\alpha V_{\mathrm{R} x}\left(2 V_{\mathrm{D} x}+1\right) \sqrt{1-x}}{4}$.

Using $\theta_{M}=0$ and (64) in (9)

$r V_{\mathrm{R}}(x)=m_{\mathrm{R}} x+\frac{\alpha^{2} V_{\mathrm{R} x}^{2}\left(2 V_{\mathrm{D} x}+1\right)(1-x)}{8}-\delta V_{\mathrm{R} x} x$.

Using $\theta_{M}=0$ and (64) in (11)

$$
\begin{aligned}
r V_{\mathrm{D}}(x)= & m_{\mathrm{D}} x-\frac{\alpha^{2} V_{\mathrm{R} x}^{2}\left(2 V_{\mathrm{D} x}-1\right)\left(2 V_{\mathrm{D} x}+1\right)(1-x)}{16} \\
& +\frac{\alpha^{2} V_{\mathrm{R} x} V_{\mathrm{D} x}\left(2 V_{\mathrm{D} x}+1\right)(1-x)}{4}-\delta V_{\mathrm{D} x} x .
\end{aligned}
$$

Using $\theta_{\mathrm{M}}=0$ and (64) in (14) we have

$r V_{\mathrm{M}}(x)=m_{\mathrm{M}} x+\frac{\alpha^{2} V_{\mathrm{R} x} V_{\mathrm{M} x}\left(2 V_{\mathrm{D} x}+1\right)(1-x)}{4}-V_{\mathrm{M} x} \delta x$.

Now, let

$V_{\mathrm{R}}(x)=T_{\mathrm{R}}+S_{\mathrm{R}} x$,

$\Rightarrow V_{\mathrm{R} x}=S_{\mathrm{R}}$.

Similarly let

$V_{\mathrm{D}}(x)=T_{\mathrm{D}}+S_{\mathrm{D}} x$,

$\Rightarrow V_{\mathrm{D} x}=S_{\mathrm{D}}$.

Further let

$V_{\mathrm{M}}(x)=T_{\mathrm{M}}+S_{\mathrm{M}} x$,

$\Rightarrow V_{\mathrm{M} x}=S_{\mathrm{M}}$.

Using (72) in (64), we have (56).

Using (70) and (72) in (65), we have (57).

Using (69), (70) and (72) in (66), we have

$r V_{\mathrm{R}}(x)=r\left(T_{\mathrm{R}}+S_{\mathrm{R}} x\right)=m_{\mathrm{R}} x+\frac{\alpha^{2} S_{\mathrm{R}}^{2}\left(2 S_{\mathrm{D}}+1\right)(1-x)}{8}-\delta S_{\mathrm{R}} x$.
Equating the coefficients of $x$, we have (61)

Using (70), (71) and (72) in (67), we have

$$
\begin{aligned}
r V_{\mathrm{D}}(x)= & r\left(T_{\mathrm{D}}+S_{\mathrm{D}} x\right)=m_{\mathrm{D}} x-\frac{\alpha^{2} S_{\mathrm{R}}^{2}\left(2 S_{\mathrm{D}}-1\right)\left(2 S_{\mathrm{D}}+1\right)(1-x)}{16} \\
& +\frac{\alpha^{2} S_{\mathrm{R}} S_{\mathrm{D}}\left(2 S_{\mathrm{D}}+1\right)(1-x)}{4}-\delta S_{\mathrm{D}} x .
\end{aligned}
$$

Equating the coefficients of $x$, we have (62)

Using (70), (72), (73) and (74) in (68), we have

$r V_{\mathrm{M}}(x)=r\left(T_{\mathrm{M}}+S_{\mathrm{M}} x\right)=m_{\mathrm{M}} x+\frac{\alpha^{2} S_{\mathrm{R}} S_{\mathrm{M}}\left(2 S_{\mathrm{D}}+1\right)(1-x)}{4}-\delta S_{\mathrm{M}} x$

Equating the coefficients of $x$, we have (63).

This result shows that in the face of the manufacturer's indifference to retail advertising, the distributor can step in to provide subsidy. However, this can only be possible if $2 S_{\mathrm{D}}>1$ as can be seen in (56).

Looking at (57), we can see the effect of the personal effort of the distributor's subsidy in retail advertising by the presence of $S_{\mathrm{D}}$ which is absent in (20) and (38) where only the retailer bears the burden of advertising.

Interestingly, we observe from (58) and (60) that this personal subsidy leads to a rise in the retailer and manufacturer's payoffs when compared with (21), (23) (nonparticipation by both the manufacturer and distributor) and (39), (41) (non-transfer of subsidy). Although it is a little bit difficult to ascertain whether the distributor is not shortchanged in the process of supporting retail advertising, we will see later using numerical illustration that compared to non-subsidy and non-transfer of subsidy he (the distributor) is better-off with this intervention.

Further with such improved payoffs for all the players, it is obvious that the channel performance will be unquestionably better compared to the previous cases discussed above.

\section{Game equilibrium characterising the provision of subsidy by the manufacturer and its transfer to the retailer}

In this section, we consider when both the manufacturer and the distributor are committed to retail advertising. The next result deals with a situation where the subsidy from the manufacturer is transferred to the retailer by the distributor.

Proposition 6 Suppose the distributor transfers the subsidy provided by the manufacturer to the retailer, then their subsidy rates are given by

$\theta_{\mathrm{D}}=\frac{2\left(4 S_{\mathrm{M}}-2 S_{\mathrm{D}}-1\right)}{\left(2 S_{\mathrm{D}}+1\right)\left(4 S_{\mathrm{M}}+2 S_{\mathrm{D}}+1\right)}+\frac{2 S_{\mathrm{D}}-1}{2 S_{\mathrm{D}}+1}$ 
and

$\theta_{\mathrm{M}}=\frac{4 S_{\mathrm{M}}-2 S_{\mathrm{D}}-1}{S_{\mathrm{R}}\left[4 S_{\mathrm{M}}+2 S_{\mathrm{D}}+1\right]}$

The advertising effort is given by

$a_{\mathrm{R}}\left(x \mid \theta_{\mathrm{D}}, \theta_{\mathrm{M}}\right)=\frac{\alpha S_{\mathrm{R}}\left(4 S_{\mathrm{M}}+2 S_{\mathrm{D}}+1\right) \sqrt{1-x}}{8}$,

while the players' payoffs are given by

$r V_{\mathrm{R}}(x)=m_{\mathrm{R}} x-\frac{\alpha^{2} S_{\mathrm{R}}^{2}\left(4 S_{\mathrm{M}}+2 S_{\mathrm{D}}+1\right)(1-x)}{16}-\delta S_{\mathrm{R}} x$

$$
\begin{aligned}
r V_{\mathrm{D}}(x)= & m_{\mathrm{D}} x+\frac{\alpha^{2} S_{\mathrm{R}}\left(4 S_{\mathrm{M}}+2 S_{\mathrm{D}}+1\right)\left(4 S_{\mathrm{M}}-2 S_{\mathrm{D}}-1\right)\left(2 S_{\mathrm{D}}-2 S_{\mathrm{R}}+1\right)(1-x)}{64\left(2 S_{\mathrm{D}}+1\right)} \\
& -\frac{\alpha^{2} S_{\mathrm{R}}^{2}\left(4 S_{\mathrm{M}}+2 S_{\mathrm{D}}+1\right)^{2}\left(2 S_{\mathrm{D}}-1\right)(1-x)}{64\left(2 S_{\mathrm{D}}+1\right)} \\
& +\frac{\alpha^{2} S_{\mathrm{R}} S_{\mathrm{D}}\left(4 S_{\mathrm{M}}+2 S_{\mathrm{D}}+1\right)(1-x)}{16}-\delta S_{\mathrm{D}} x,
\end{aligned}
$$

$r V_{\mathrm{M}}(x)=m_{\mathrm{M}} x-\frac{\alpha^{2} S_{\mathrm{R}}\left(4 S_{\mathrm{M}}+2 S_{\mathrm{D}}+1\right)\left(4 S_{\mathrm{M}}-2 S_{\mathrm{D}}-1\right)(1-x)}{64} \quad$ Using (84) in (8), we have

$$
+\frac{\alpha^{2} S_{\mathrm{R}} S_{\mathrm{M}}\left(4 S_{\mathrm{M}}+2 S_{\mathrm{D}}+1\right)(1-x)}{8}-\delta S_{\mathrm{M}} x,
$$

where

$$
\begin{aligned}
S_{\mathrm{R}}= & \frac{16 m_{\mathrm{R}}}{\alpha^{2} S_{\mathrm{R}}\left(4 S_{\mathrm{M}}+2 S_{\mathrm{D}}+1\right)+16(r+\delta)} \\
S_{\mathrm{D}}= & \frac{64 m_{\mathrm{D}}\left(2 S_{\mathrm{D}}+1\right)-\alpha^{2} S_{\mathrm{R}}\left(4 S_{\mathrm{M}}+2 S_{\mathrm{D}}+1\right)\left(4 S_{\mathrm{M}}-2 S_{\mathrm{D}}-1\right)\left(2 S_{\mathrm{D}}-2 S_{\mathrm{R}}+1\right)}{8\left(2 S_{\mathrm{D}}+1\right)\left[\alpha^{2} S_{\mathrm{R}}\left(4 S_{\mathrm{M}}+2 S_{\mathrm{D}}+1\right)+8(r+\delta)\right]} \\
& +\frac{\alpha^{2} S_{\mathrm{R}}^{2}\left(4 S_{\mathrm{M}}+2 S_{\mathrm{D}}+1\right)^{2}\left(2 S_{\mathrm{D}}-1\right)}{8\left(2 S_{\mathrm{D}}+1\right)\left[\alpha^{2} S_{\mathrm{R}}\left(4 S_{\mathrm{M}}+2 S_{\mathrm{D}}+1\right)+8(r+\delta)\right]}
\end{aligned}
$$

Putting (84) into (9), we have

$$
S_{\mathrm{M}}=\frac{64 m_{\mathrm{M}}+\alpha^{2} S_{\mathrm{R}}\left(4 S_{\mathrm{M}}+2 S_{\mathrm{D}}+1\right)\left(4 S_{\mathrm{M}}-2 S_{\mathrm{D}}-1\right)}{8 \alpha^{2} S_{\mathrm{R}}\left(4 S_{\mathrm{M}}+2 S_{\mathrm{D}}+1\right)+64(r+\delta)}
$$

$$
\begin{aligned}
r V_{\mathrm{R}}(x) & =m_{\mathrm{R}} x+\frac{\alpha^{2} V_{\mathrm{R} x}^{2}(1-x)}{4\left[1-\left(\frac{2\left(4 V_{\mathrm{M} x}-2 V_{\mathrm{D} x}-1\right)}{\left(2 V_{\mathrm{D} x}+1\right)\left(4 V_{\mathrm{M} x}+2 V_{\mathrm{D} x}+1\right)}+\frac{2 V_{\mathrm{D} x}-1}{2 V_{\mathrm{D} x}+1}\right)\right]}-\delta V_{\mathrm{R} x} x \\
& =m_{\mathrm{R}} x+\frac{\alpha^{2} V_{\mathrm{R} x}^{2}\left(4 V_{\mathrm{M} x}+2 V_{\mathrm{D} x}+1\right)(1-x)}{16}-\delta V_{\mathrm{R} x} x
\end{aligned}
$$


Using (84) and (85) in (11), we have

$$
\begin{aligned}
r V_{\mathrm{D}}(x)= & m_{\mathrm{D}} x+\frac{\alpha^{2} V_{\mathrm{R} x}^{2}\left(\frac{4 V_{\mathrm{M} x}-2 V_{\mathrm{D} x}-1}{V_{\mathrm{R} x}\left[4 V_{\mathrm{M} x}+2 V_{\mathrm{D} x}+1\right]}\right)(1-x)}{4\left[1-\left(\frac{2\left(4 V_{\mathrm{M} x}-2 V_{\mathrm{D} x}-1\right)}{\left(2 V_{\mathrm{D} x}+1\right)\left(4 V_{\mathrm{M} x}+2 V_{\mathrm{D} x}+1\right)}+\frac{2 V_{\mathrm{D} x}-1}{2 V_{\mathrm{D} x}+1}\right)\right]^{2}} \\
& -\frac{\alpha^{2} V_{\mathrm{R} x}^{2}\left(\frac{2\left(4 V_{\mathrm{M} x}-2 V_{\mathrm{D} x}-1\right)}{\left(2 V_{\mathrm{D} x}+1\right)\left(4 V_{\mathrm{M} x}+2 V_{\mathrm{D} x}+1\right)}+\frac{2 V_{\mathrm{D} x}-1}{2 V_{\mathrm{D} x}+1}\right)(1-x)}{4\left[1-\left(\frac{2\left(4 V_{\mathrm{M} x}-2 V_{\mathrm{D} x}-1\right)}{\left(2 V_{\mathrm{D} x}+1\right)\left(4 V_{\mathrm{M} x}+2 V_{\mathrm{D} x}+1\right)}+\frac{2 V_{\mathrm{D} x}-1}{2 V_{\mathrm{D} x}+1}\right)\right]^{2}} \\
& +\frac{\alpha^{2} V_{\mathrm{D} x} V_{\mathrm{R} x}(1-x)}{4\left[1-\left(\frac{2\left(4 V_{\mathrm{M} x}-2 V_{\mathrm{D} x}-1\right)}{\left(2 V_{\mathrm{D} x}+1\right)\left(4 V_{\mathrm{M} x}+2 V_{\mathrm{D} x}+1\right)}+\frac{2 V_{\mathrm{D} x}-1}{2 V_{\mathrm{D} x}+1}\right)\right]}-V_{\mathrm{D} x} \delta x \\
= & m_{\mathrm{D}} x+\left\{\frac{\alpha^{2} V_{\mathrm{R} x}\left(4 V_{\mathrm{M} x}+2 V_{\mathrm{D} x}+1\right)\left(4 V_{\mathrm{M} x}-2 V_{\mathrm{D} x}-1\right)\left(2 V_{\mathrm{D} x}-2 V_{\mathrm{R} x}+1\right)}{64\left(2 V_{\mathrm{D} x}+1\right)}\right. \\
& -\frac{\alpha^{2} V_{\mathrm{R} x}\left(4 V_{\mathrm{M} x}+2 V_{\mathrm{D} x}+1\right)^{2}\left(2 V_{\mathrm{D} x}-1\right)}{64\left(2 V_{\mathrm{D} x}+1\right)} \\
& \left.+\frac{2 \alpha^{2} V_{\mathrm{R} x} V_{\mathrm{D} x}\left(4 V_{\mathrm{M} x}+2 V_{\mathrm{D} x}+1\right)}{16}\right\}(1-x)-V_{\mathrm{D} x} \delta x .
\end{aligned}
$$

Using (84) and (85) in (14), we have

$$
\begin{aligned}
r V_{\mathrm{M}}(x)= & m_{\mathrm{M}} x-\left\{\frac{\alpha^{2} V_{\mathrm{R} x}\left(\frac{4 V_{\mathrm{M} x}-2 V_{\mathrm{D} x}-1}{V_{\mathrm{R} x}\left(4 V_{\mathrm{M} x}+2 V_{\mathrm{D} x}+1\right)}\right)}{4\left(\frac{4}{4 V_{\mathrm{M} x}+2 V_{\mathrm{D} x}+1}\right)^{2}}-\frac{\alpha^{2} V_{\mathrm{R} x} V_{\mathrm{M} x}}{2\left(\frac{4}{4 V_{\mathrm{M} x}+2 V_{\mathrm{D} x}+1}\right)}\right\}(1-x)-V_{\mathrm{M} x} \delta x \\
= & m_{\mathrm{M}} x-\frac{\alpha^{2} V_{\mathrm{R} x}\left(4 V_{\mathrm{M} x}+2 V_{\mathrm{D} x}+1\right)\left(4 V_{\mathrm{M} x}-2 V_{\mathrm{D} x}-1\right)(1-x)}{64} \\
& +\frac{\alpha^{2} V_{\mathrm{R} x} V_{\mathrm{M} x}\left(4 V_{\mathrm{M} x}+2 V_{\mathrm{D} x}+1\right)(1-x)}{8}-V_{\mathrm{M} x} \delta x .
\end{aligned}
$$

Let

$$
\begin{aligned}
& V_{\mathrm{R}}(x)=T_{\mathrm{R}}+S_{\mathrm{R}} x, \\
& \Rightarrow V_{\mathrm{R} x}=S_{\mathrm{R}} .
\end{aligned}
$$

Similarly let

$V_{\mathrm{D}}(x)=T_{\mathrm{D}}+S_{\mathrm{D}} x$

$\Rightarrow V_{\mathrm{D} x}=S_{\mathrm{D}}$.

We also let

$V_{\mathrm{M}}(x)=T_{\mathrm{M}}+S_{\mathrm{M}} x$,

$\Rightarrow V_{\mathrm{M} x}=S_{\mathrm{M}}$.
Also using (91), (93) and (95) in (85), we have (76).

Further using (91), (93) and (95) in (86), we have (77)

Now, considering the value functions we have that by using (90), (91), (93) and (95) in (87) becomes

$$
\begin{aligned}
r V_{\mathrm{R}}(x)= & r\left(T_{\mathrm{R}}+S_{\mathrm{R}} x\right)=m_{\mathrm{R}} x \\
& +\frac{\alpha^{2} S_{\mathrm{R}}^{2}\left(4 S_{\mathrm{M}}+2 S_{\mathrm{D}}+1\right)(1-x)}{16}-\delta S_{\mathrm{R}} x .
\end{aligned}
$$

Equating the coefficients of $x$, we have (81).

Using (91), (92), (93), (95) in (88)

Using (93) and (95) in (84), we have (75). 


$$
\begin{aligned}
r V_{\mathrm{D}}(x)= & r\left(T_{\mathrm{D}}+S_{\mathrm{D}} x\right) \\
= & m_{\mathrm{D}} x+\frac{\alpha^{2} S_{\mathrm{R}}\left(4 S_{\mathrm{M}}+2 S_{\mathrm{D}}+1\right)\left(4 S_{\mathrm{M}}-2 S_{\mathrm{D}}-1\right)\left(2 S_{\mathrm{D}}-2 S_{\mathrm{R}}+1\right)(1-x)}{64\left(2 S_{\mathrm{D}}+1\right)} \\
& -\frac{\alpha^{2} S_{\mathrm{R}}^{2}\left(4 S_{\mathrm{M}}+2 S_{\mathrm{D}}+1\right)^{2}\left(2 S_{\mathrm{D}}-1\right)(1-x)}{64\left(2 S_{\mathrm{D}}+1\right)} \\
& +\frac{\alpha^{2} S_{\mathrm{R}} S_{\mathrm{D}}\left(4 S_{\mathrm{M}}+2 S_{\mathrm{D}}+1\right)(1-x)}{16}-\delta S_{\mathrm{D}} x
\end{aligned}
$$

Equating the coefficients of $x$, we have (82).

Using (91) (93), (94) and (95) in (89), we have

$$
\begin{aligned}
r V_{\mathrm{M}}(x)= & r\left(T_{\mathrm{M}}+S_{\mathrm{M}} x\right)=m_{\mathrm{M}} x-\frac{\alpha^{2} S_{\mathrm{R}}\left(4 S_{\mathrm{M}}+2 S_{\mathrm{D}}+1\right)\left(4 S_{\mathrm{M}}-2 S_{\mathrm{D}}-1\right)(1-x)}{64} \\
& +\frac{\alpha^{2} S_{\mathrm{R}} S_{\mathrm{M}}\left(4 S_{\mathrm{M}}+2 S_{\mathrm{D}}+1\right)(1-x)}{8}-\delta S_{\mathrm{M}} x .
\end{aligned}
$$

Equating the coefficients of $x$, we have (83).

With the provision of subsidy by the manufacturer and subsequent transfer by the distributor to the retailer, we observe that in comparison with (20), (38) and (65) the retail advertising effort (77) is higher. This also reflects in the payoff (78). Mere looking at (79) and (80), we may not be able to ascertain whether the distributor and the manufacturer benefit from the increase in advertising effort. However, observe that the retailer is the actual source of the players' revenues/payoffs. Thus, having increased effort, the product awareness share will certainly increase, which will lead to more patronage by end users. This will certainly increase both the distributor and manufacturer's payoffs as we will see later in the numerical illustration. Obviously, this increased commitment will lead to better channel payoffs when compared with the other channel payoff in the other scenarios discussed above.

\section{Numerical illustrations}

This section considers numerical illustrations of the discussion/results in this work. To simplify the illustrations, we let the subscripts $\left(\theta_{\mathrm{D}}=\theta_{\mathrm{M}}=0\right), \quad\left(\theta_{\mathrm{D}}=0, \theta_{\mathrm{M}}>0\right)$, $\left(\theta_{\mathrm{D}}>0, \theta_{\mathrm{M}}=0\right)$ and $\left(\theta_{\mathrm{D}}, \theta_{\mathrm{M}}>0\right)$ represent a situation where both the manufacturer and the distributor do not participate in retail advertising; a situation where the distributor withholds the subsidy provided by the manufacturer for retail advertising; a situation where the distributor provides subsidy in the absence of the manufacturer's participation; and a situation where both the manufacturer and the distributor participate in retail advertising, respectively. For instance, $V_{R\left(\theta_{\mathrm{D}}=0, \theta_{\mathrm{M}}>0\right)}$ represents the retailer's payoff for a situation where the manufacturer provides subsidy (that is $\theta_{\mathrm{D}}=0$ ), but the distributor fails to transfer the provided subsidy (that is $\left.\theta_{\mathrm{M}}\right)$. In general, we say that it is a situation where subsidy is withheld by the distributor. Similarly, for the various situations (scenarios) we let the channel payoff to be

$V_{\left(\theta_{\mathrm{D}}=\theta_{\mathrm{M}}=0\right)}=V_{R\left(\theta_{\mathrm{D}}=\theta_{\mathrm{M}}=0\right)}+V_{D\left(\theta_{\mathrm{D}}=\theta_{\mathrm{M}}=0\right)}+V_{M\left(\theta_{\mathrm{D}}=\theta_{\mathrm{M}}=0\right)} ;$

$V_{\left(\theta_{\mathrm{D}}=0, \theta_{\mathrm{M}}>0\right)}=V_{R\left(\theta_{\mathrm{D}}=0, \theta_{\mathrm{M}}>0\right)}+V_{D\left(\theta_{\mathrm{D}}=0, \theta_{\mathrm{M}}>0\right)}+V_{M\left(\theta_{\mathrm{D}}=0, \theta_{\mathrm{M}}>0\right)} ;$

$V_{\left(\theta_{\mathrm{D}}>0, \theta_{\mathrm{M}}=0\right)}=V_{\mathrm{R}\left(\theta_{\mathrm{D}}>0, \theta_{\mathrm{M}}=0\right)}+V_{\mathrm{D}\left(\theta_{\mathrm{D}}>0, \theta_{\mathrm{M}}=0\right)}+V_{\mathrm{M}\left(\theta_{\mathrm{D}}>0, \theta_{\mathrm{M}}=0\right)}$ and

$V_{\left(\theta_{\mathrm{D}}, \theta_{\mathrm{M}}>0\right)}=V_{\mathrm{R}\left(\theta_{\mathrm{D}}, \theta_{\mathrm{M}}>0\right)}+V_{\mathrm{D}\left(\theta_{\mathrm{D}}, \theta_{\mathrm{M}}>0\right)}+V_{\mathrm{M}\left(\theta_{\mathrm{D}}, \theta_{\mathrm{M}}>0\right)}$.

\section{Parameter values}

The choice of the parameter values is very important in the illustration of the above results. Choosing the parameter values arbitrarily without recourse to the model requirements will certainly lead to misleading results and conclusions. We thus choose them based on the model assumptions. We recall that the advertising effectiveness measures the response to advertising. Since $\alpha \in[0,1]$, we let $\alpha=0.3$. Note that ideally, the rate of decay of the awareness $\delta$ should be less than the advertising effectiveness. As such we let $\delta=0.1$. Since the game is assumed to be played on an infinite horizon, and the players are considered to be foresighted, we let $r=0.05$. The manufacturer is the Stackelberg game leader, and thus, he enjoys the first mover's advantage. This makes his margin larger than that of the distributor who is the first follower. The retailer is the last in the channel hierarchy. His margin is therefore considered to be the least of all the margins. Thus, we have that $m_{\mathrm{M}}>m_{\mathrm{D}}>m_{\mathrm{R}}>0$, and let $m_{\mathrm{R}}=0.30$, $m_{\mathrm{D}}=0.35$, and $m_{\mathrm{M}}=0.40$. 


\section{Comparison of the Retailer's payoffs}

From Fig. 1, we observe that the retailer is worst-off with both non-provision and non-transfer of the manufacturer's provided subsidy. When compared with non-provision and non-transfer of the provided subsidy, the retailer is better-off with the distributor's intervention in the absence the manufacturer's participation in advertising. However, his payoff is best with provision and transfer of subsidy.

$$
\begin{array}{ccc}
\text { F u r t h e r, } \quad \text { t h e } \quad \text { f a c t } \quad \text { t h a t } \\
V_{\mathrm{R}\left(\theta_{\mathrm{D}}, \theta_{\mathrm{M}}>0\right)}>V_{\mathrm{R}\left(\theta_{\mathrm{D}}>0, \theta_{\mathrm{M}}=0\right)}>V_{\mathrm{R}\left(\theta_{\mathrm{D}}=0, \theta_{\mathrm{M}}>0\right)}
\end{array}
$$

shows that the transfer of subsidy is very important to the retailer and should not just be the distributor's personal concern.

\section{Comparison of the Distributor's payoffs}

From Fig. 2, we observe that the distributor's payoff is worstoff when he withholds the subsidy. In fact, it is better for him that the manufacturer does not provide any subsidy than that the retailer is not given this subsidy. A further consideration shows that the distributor should take the initiative to subsidise retail advertising in the absence of the manufacturer's participation. We further observe that the transfer of the provided subsidy is of paramount importance to the distributor. Clearly, this is the best option for him.

\section{Comparison of the Manufacturer's payoffs}

From Fig. 3, we note that the manufacturer is worst-off when neither the manufacturer nor the distributor participates in retail advertising. Thus, their individual as well as group participation in retail advertising is very important to the manufacturer.

Now, comparing when the distributor withholds the subsidy and when he personally takes the initiative to support the retailer, we observe that the manufacturer's payoff is worst-off with non-transfer of the provided subsidy. This suggests that the participation of the distributor is crucial for the manufacturer's payoff. Thus, being the channel leader the manufacturer can adopt measures that can constrain the distributor to transfer the provided subsidy, or discourage him from withholding the provided subsidy. Further, we note that the manufacturer is better-off with both the manufacturer and distributor's participation in retail advertising through subsidy.
Fig. 1 A comparison of the retailer's payoffs characterising the four channel structures

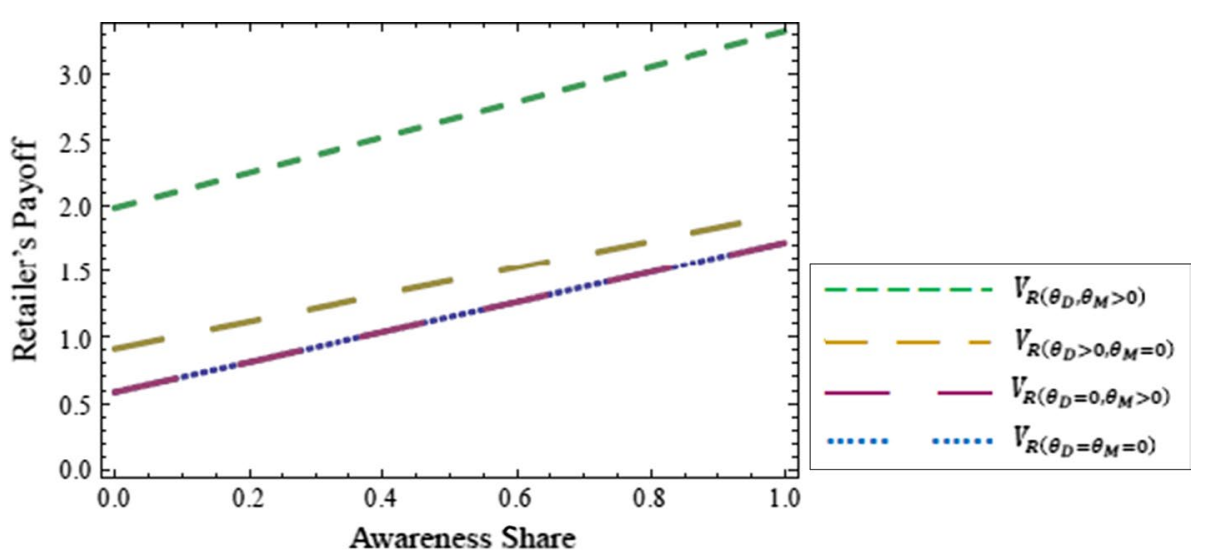

Fig. 2 A comparison of the distributor's payoffs characterising the four channel structures

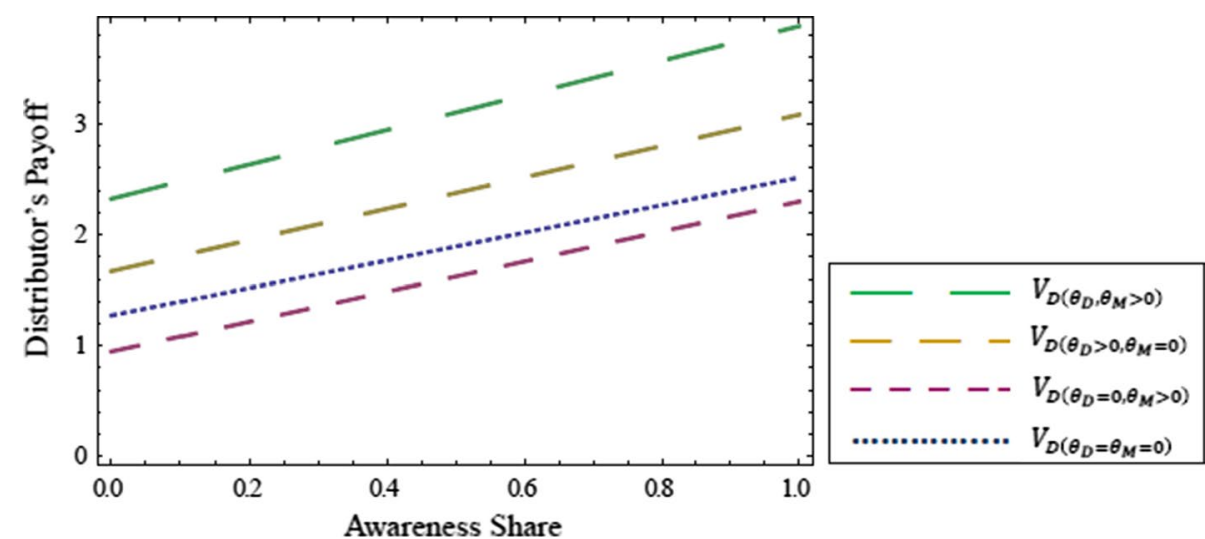


Fig. 3 A comparison of the manufacturer's payoffs characterising the four channel structures

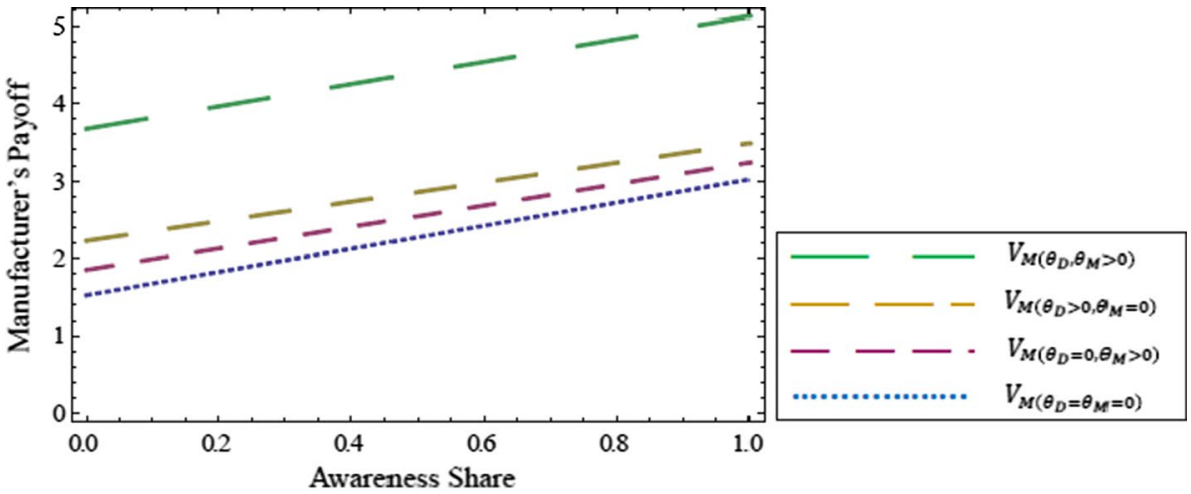

\section{Comparison of channel payoffs}

Figure 4 shows that non-transfer of subsidy is as bad as nonparticipation of both the manufacturer and distributor. Thus, the entire channel suffers when the distributor withholds the subsidy meant for retail advertising. On the other hand, the channel payoff is better-off with at least the distributor's personal intervention subsidy to the retailer when compared with non-provision and non-transfer of subsidy. The channel payoff is best with subsidy transfer. Thus, a collective concern is very important for all the channel members.

\section{Concluding remarks}

In this work, we considered a cooperative advertising supply chain involving a manufacturer, a distributor and a retailer. While only the retailer is involved in advertising, both the manufacturer and distributor indirectly participate in retail advertising through subsidy. The work considered a decentralised channel structure using four-game scenarios: nonparticipation, non-transfer of subsidy, distributor's intervention subsidy and transfer of subsidy. For each of these structures, we determined the advertising effort, the participation rates, the player's payoffs and the channel payoff.

In this work, we added to the cooperative advertising literature by incorporating the distributor into the traditional manufacturer-retailer cooperative advertising supply chain. Thus, we have a manufacturer-distributor-retailer cooperative advertising supply chain. This is a more realistic situation since manufacturers usually deal with their retailers through a middleman which in this case is the distributor. Further, works on cooperative advertising usually consider situations where the manufacturer directly provides subsidy to the retailer. This work presents a modification in which the manufacturer's subsidy for retail advertising passes through the distributor.

\section{Managerial implications}

We observed that commitment towards retail advertising is worst for non-participation. This is the same for non-transfer of subsidy. With the distributor's intervention subsidy, the advertising effort increases and is best with the transfer of manufacturer's subsidy to the retailer. In the absence of participation, individual player's payoff is worst, but best with transfer of subsidy. Thus, the distributor's participation in retail advertising is crucial to all the players. In fact in the absence of the manufacturer's participation, the distributor's intervention subsidy is very important. This is because with his intervention/participation all the players' payoffs as well as the channel payoff are better-off compared to non-participation and non-transfer of subsidy. Further, for optimality, it is necessary that each player should take note of the
Fig. 4 A comparison of the channel payoffs characterising the four channel structures

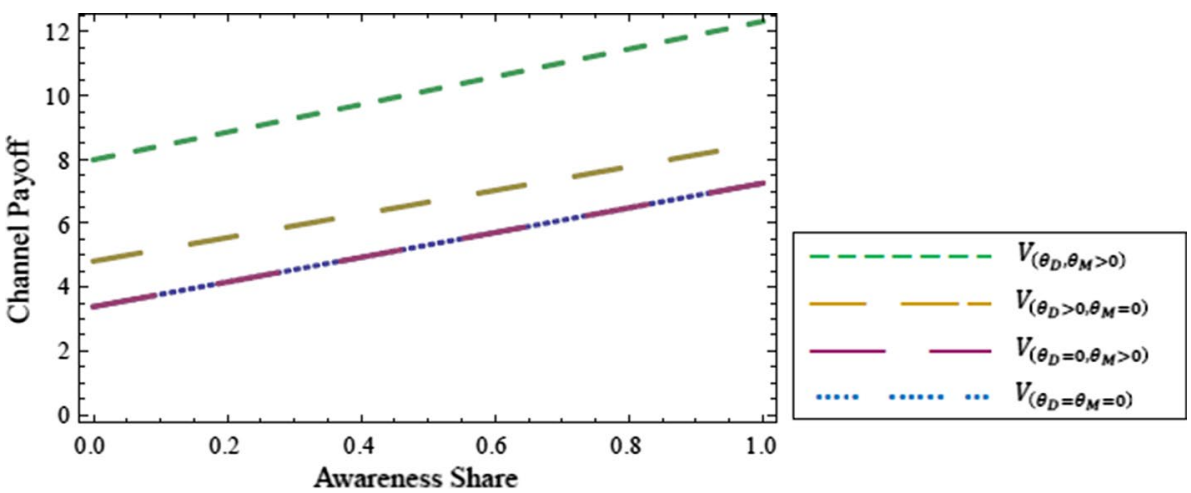


particular prevailing setting, whether it is non-participation by both the manufacturer and the distributor; non-transfer by the distributor; intervention by the distributor; transfer of manufacturer's provided subsidy by the distributor. They should implement their respective optimal strategies to avoid being short-changed, and for better channel payoff.

\section{Limitation and extension}

In this work, only the retailer is involved in advertising. A situation may require an aggressive advertising approach in which all three players may be directly involved in advertising in addition to provision of subsidy. We restricted the work to only three players. An extension may consider multiple manufacturers-distributors-retailers supply chain.

Open Access This article is distributed under the terms of the Creative Commons Attribution 4.0 International License (http://creativeco mmons.org/licenses/by/4.0/), which permits unrestricted use, distribution, and reproduction in any medium, provided you give appropriate credit to the original author(s) and the source, provide a link to the Creative Commons license, and indicate if changes were made.

\section{References}

Aust G, Buscher U (2014) Vertical cooperative advertising in a retailer duopoly. Comput Ind Eng 72:247-254

Bergen M, John G (1997) Understanding cooperative advertising participation rates in conventional channels. J Market Res 34(3):357-369

Berger PD (1972) Vertical cooperative advertising ventures. J Market Res 9(3):309-312

Carmichael F (2005) A guide to game theory. Pearson Education, New York

Chintagunta PK, Jain DC (1992) A dynamic model of channel member strategies for marketing expenditures. Market Sci 11(2):168-188

Chintagunta PK, Vilcassim NJ (1992) An empirical investigation of advertising strategies in a dynamic duopoly. Management Science 38(9):1230-1244

Chintagunta PK, Vilcassim NJ (1994) Marketing investment decisions in a dynamic duopoly: a model and empirical analysis. Int J Res Mark 11(3):287-306

Chutani A, Sethi SP (2012) Cooperative advertising in a dynamic retail market oligopoly. Dyn Games Appl 2(4):347-375

Chutani A, Sethi SP (2014) A feedback Stackelberg game of cooperative advertising in a durable goods oligopoly. In: Haunschmied J, Veliov VM, Wrzaczek S (eds) Dynamic Games in Economics. Springer, Berlin, pp 89-114

Dant RP, Berger PD (1996) Modeling cooperative advertising decisions in franchising. J Oper Res Soc 47(9):1120-1136

Dutta S, Bergen M, John G, Rao A (1995) Variations in the contractual terms of cooperative advertising contracts: an empirical investigation. Market Lett 6(1):15-22

Ezimadu PE, Nwozo CR (2017) Stochastic cooperative advertising in a manufacturer-retailer decentralized supply channel. J Ind Eng Int 13:1-12

Fruchter GE, Kalish S (1998) Dynamic promotional budgeting and media allocation. Eur J Oper Res 111(1):15-27

Geckil IK, Anderson PL (2009) Applied game theory and strategic behaviour. CRC Press, Boca Raton
Ghadimi S, Szidarovszky F, Farahani RZ, Khiabani AY (2013) Coordination of advertising in supply chain management with cooperating manufacturer and retailers. IMA J Manag Math 24(1):1-19

He X, Prasad A, Sethi SP (2009) Cooperative advertising and pricing in a dynamic stochastic supply chain: feedback Stackelberg strategies. Prod Oper Manag 18(1):78-94

He X, Krshnamoorthy A, Prasad A, Sethi SP (2011) Retail competition and cooperative advertising. Oper Res Lett 39:11-16

He Y, Liu Z, Usman K (2014) Coordination of cooperative advertising in a two-period fashion and textiles supply chain. Math Probl Eng. https://doi.org/10.11552/2014/356726

Huang J, Leng M, Liang L (2012) Recent developments in dynamic advertising research. Eur J Oper Res 220(3):591-609

Huang Z, Li SX, Mahajan V (2002) An analysis of manufacturerretailer supply chain coordination in cooperative advertising. Decis Sci 33(3):469-494

JaliliNaini SG, Aliahmadi A, Eskandari JM (2010) Designing a mixed performance measurement system for environmental supply chain management using evolutionary game theory and balanced scorecard: a case study of an auto industry supply chain. Resour Conserv Recycl 55(6):593-603

Jørgensen S, Zaccour G (2014) A survey of game-theoretic models of cooperative Advertising. Eur J Oper Res 237(1):1-14

Jørgensen S, Sigue SP, Zaccour G (2000) Dynamic cooperative advertising in a channel. J Retail 76(1):71-92

Jørgensen S, Taboubi S, Zaccour G (2003) Retail promotions with negative brand image effects: is cooperation possible? Eur J Oper Res 150(2):395-405

Karray S, Amin SH (2015) Cooperative advertising in a supply chain with retail competition. Int Game Theory Rev 9(2):151-167

Karray S, Zaccour G (2005) A differential game of advertising for national brand and store brands. In: Haurie A, Zaccour G (eds) Dynamic games: theory and applications. Springer, Berlin, pp 213-229

Kermani MAMA, Navidi H, Alborzi F (2012) A novel method for supplier selection by two competitors, including multiple criteria. Int J Comput Integr Manuf 25(6):527-535

Kimball GE (1957) Some industrial applications of military Operations Research methods. Oper Res 5:201-204

McCain R (2014) Game theory: a nontechnical introduction to the analysis of strategy. World Scientific Publishing, London

Nagler MG (2006) An exploratory analysis of the determinants of cooperative advertising participation rates. Market Lett 17(2):91-102

Naik PA, Raman K, Winer RS (2005) Planning marketing-mix strategies in the presence of interactions. Market Sci 24(1):25-34

Nerlove M, Arrow KJ (1962) Optimal advertising policy under dynamic conditions. Economica 29:129-142

Prasad A, Sethi SP (2004) Competitive advertising under uncertainty: a stochastic differential game approach. J Optim Theory Appl 123(1):163-185

Sethi SP (1979) Optimal advertising policy with contagion model. J Optim Theory Appl 29:615-627

Sethi SP (1983) Deterministic and stochastic optimization of a dynamic advertising model. Optimal Control Appl Methods 4(2):179-184

Seyedesfahani M, Biazaran M, Gharakhani M (2011) A game theoretic approach to coordinate pricing and vertical co-op advertising in manufacturer-retailer supply chains. Eur J Oper Res 211(1):263-273

Taylor JR (1978) How to start and succeed in a business of your own. Reston Publishing Company, Virgina, USA

Vidale ML, Wolfe HB (1957) An operations research study of sales response to advertising. Oper Res 5(3):370-381

Wang S, Zhou Y, Min J, Zhong Y (2011) Coordination of cooperative advertising models in a one-manufacturer two-retailer supply chain system. Comput Ind Eng 61(4):1053-1071 
Webster FE (1976) The role of the industrial distributor in marketing strategy. J Market 40(3):10-16

Xiao T, Qi X (2008) Price competition, cost and demand disruptions and coordination of a supply chain with one manufacturer and two competing retailers. Omega 36(5):741-753

Yu H, Zeng AZ, Zhao L (2009) Analyzing the evolutionary stability of the vendor managed inventory supply chains. Comput Ind Eng $56(1): 274-282$
Zhang J, Xie J (2012) A game theoretic study of cooperative advertising with multiple retailers in a distribution channel. J Syst Sci Syst Eng 21(1):37-55

Zhang J, Li J, Lu L, Dai R (2017) Supply chain performance for deteriorating items with cooperative advertising. J Syst Sci Syst Eng 26(1):23-49

Zhu Q, Dou Y (2008) Evolutionary game model between governments and core enterprises in greening supply chains. Syst Eng Theory Pract 5:85-89 